\title{
An assessment of diabetes-dependent quality of life (ADDQoL) in women and men in Poland with type 1 and type 2 diabetes
}

\author{
Ewelina Bąk ${ }^{1, A-F} \oplus$, Zofia Nowak-Kapusta ${ }^{2, D \oplus}{ }^{\circ}$, Dorota Dobrzyń-Matusiak ${ }^{3, D \oplus}$, Ewa Marcisz-Dyla ${ }^{4, D \odot}$, \\ Czesław Marcisz ${ }^{5, D-F} \oplus$, Sylwia Krzemińska6,D \\ ${ }^{1}$ University of Bielsko-Biala, Faculty of Health Sciences, Bielsko-Biala, Poland \\ ${ }^{2}$ Department of Health Promotion and Community Nursing, School of Health Sciences, Medical University of Silesia, \\ Katowice, Poland \\ ${ }^{3}$ Department of Nursing Propaedeutics, School of Health Sciences, Medical University of Silesia, Katowice, Poland \\ ${ }^{4}$ Department of Anxiety Disorders, Hospital of Ministry of Internal Affairs, Katowice, Poland \\ ${ }^{5}$ Department of Gerontology and Geriatric Nursing, School of Health Sciences, Medical University of Silesia, Katowice, \\ Poland \\ ${ }^{6}$ Medical University, Department of Clinical Nursing Faculty of Health Sciences, Wroclaw, Poland \\ A - Research concept and design, B - Collection and/or assembly of data, C - Data analysis and interpretation, \\ $D$ - Writing the article, E - Critical revision of the article, F - Final approval of article
}

Bąk E, Nowak-Kapusta Z, Dobrzyn-Matusiak D, Marcisz-Dyla E, Marcisz C, Krzemińska S. An assessment of diabetes-dependent quality of life (ADDQoL) in women and men in Poland with type 1 and type 2 diabetes. Ann Agric Environ Med. 2019; 26(3): 429-438. doi: 10.26444/aaem/99959

\section{Abstract}

Introduction. Quality of Life (QoL) of Polish women and men with type 1 diabetes (T1DM) and type 2 diabetes (T2DM) was analyzed, taking into consideration acceptance of the illness, the occurrence of depression, complications of diabetes, concentration of glycated haemoglobin, and demographic factors.

Materials and method. The study was conducted among 115 patients with T1DM and 215 patients with T2DM aged 18-60. The patients were divided into women and men. The tool applied for studying QoL was the Polish language version of the Audit of diabetes-dependent QoL questionnaire(ADDQoL) comprising 2 questions related to the general QoL and 19 domains related to aspects of life. Each domain included 2 components: Impact and Importance, and their product determined the value of the weighted impact score. The Acceptance of Illness Scale, Beck Depression Inventory and studied demographic and clinical parameters were also applied.

Results. Patients with both types of diabetes demonstrated a negative influence of the disease in all domains of ADDQoL. Values of the average weighted impact of ADDQoL showed significant associations with diabetic complications in T1DM and gender and depressive symptoms in T2DM. Diabetes negatively affects the QoL of diabetic patients in Poland, especially regarding freedom to eat and to drink and sex life in both genders in T1DM, and freedom to eat and drink, and feelings about the future in both genders, and working life and sex life in T2DM men.

Conclusions. Risk factors for worse QoL are: the occurrence of diabetes complications in T1DM patients and male gender and depression in T2DM patients.

\section{Key words}

quality of life, Beck Depression Inventory, acceptance of illness scale, type 1 and 2 diabetes, ADDQoL

\section{Abbreviations}

ADDQoL = the Audit of Diabetes-Dependent Quality of Life, AIS = Acceptance of Illness Scale, AWI = average value of the weighted impact, BDI = Beck Depression Inventory, BMI = Body Mass Index, DAFNE = Dose Adjustment For Normal Eating, HbA1c = glycated hemoglobin, NA = not applicable, $\mathbf{r}=$ Spearman's correlation coefficient, $\mathbf{Q} \mathbf{L L}=\mathbf{Q}$ uality of Life, $\mathbf{S D}=\mathbf{s t a n d a r d}$ deviation, T1DM = patients with type 1 diabetes, T2DM = patients with type 2 diabetes, $\mathbf{W I}=$ values of the impact rating

\section{INTRODUCTION}

Based on data provided by the Polish National Health Fund and the Diabetes-Coalition (Koalicja-Cukrzyca) organization, it is considered that in Poland there are about 3.5 million people with diabetes which constitutes $9 \%$ of the entire population. The disease was diagnosed in 2.15 million people with type 2 diabetes (T2DM) and in 180,000 people with type 1 diabetes (T1DM) [1].

Address for correspondence: Ewelina Bąk, Faculty of Health Sciences, University of Bielsko-Biala, Poland, ul. Willowa 2, 43-309 Bielsko-Biała, Poland e-mail: ewelina.bak76@wp.pl

Received: 23.10.2018; accepted: 24.11.2018; first published: 10.12.2018
It has been proved that diabetes has a negative influence on the physical and psychological condition of the patient and on his/her social functioning, and the disease therefore leads to the deterioration of the level of quality of life (QoL) of patients with both T1DM $[2,3]$ and T2DM [4-17]. A review of the literature demonstrates that studies related to QoL of patients with diabetes have been carried out mainly among those with T2DM.

The tool applied for assessing the QoL of patients with diabetes was mainly the Audit of Diabetes Dependent Quality of Life (ADDQoL) scale, which is recommended by many diabetes research institutes as an individualized measure of diabetes-specific QoL. The scale is composed of 
a general assessment comprising two initial items to measure present QoL and diabetes-specific QoL, as well as a detailed assessment comprising 19 specific domains [18]. Studies applying the ADDQoL scale, which was verified among many populations differing in terms of culture, ethnicity and the environment, were carried out in both types of diabetes in many countries, i.e. England [3], Slovenia [6], Greece [7], Turkey [14], Romania [8], Portugal [19], Korea [15], Taiwan [5, 16], China [17], Malaysia [13, 20], Chinese-speaking participants in Singapore [21], Argentina [9], Australia [12], and north-eastern United States (among Spanish-speaking patients of Puerto-Rican nationality residing there) [10]. It was found that in societies inhabiting various parts and regions of the world the influence of diabetes on particular domains of the QoL of persons with this disease was differentiated. QoL was impaired in patients with diabetes, especially in the "freedom to eat" domain $[5,7,9,11,12$, $13,19,22,23]$, "close personal relationship", "sex life", "selfconfidence", "motivation to achieve things" [11], "feelings about the future," and "freedom to drink" [11,23]. Diabetes had the least negative influence on the "people's reactions" domain $[6,7,22]$. It was found that the worse QoL of patients with diabetes was associated with the occurrence symptoms of depression $[8,10,15,20,24]$.

Taking into account the fact that in the individual countries the study populations of patients with diabetes differed in terms of socio-demographic, ethnicity, cultural, lifestyle and medical care, the determination of their QoL required determining the psychometric properties of the questionnaire written in the mother tongue of the assessed population. It has been shown that the results of the psychometric properties of ADDQoL have proved that this questionnaire is a reliable tool for a comprehensive evaluation of the QoL in adults with diabetes [25] - also in Polish language version [26]. In many studies considering the QoL of patients with diabetes the ADDQoL was used $[22,19,25]$. In Poland, the effect of type 2 diabetes on the QoL was investigated using ADDQoL [27], while other authors used the EQ-5d and SF-36 questionnaire [28] and the WHOQOL BREF questionnaire [29, 30].

\section{OBJECTIVE}

The aim of the paper was to determine the influence of T1DM and T2DM on the level of QoL, taking into consideration the particular domains included in the ADDQoL as well as examining the associations between QoL, the degree of lowered mood and acceptance of the illness, complications of diabetes, HbAlc and the demographic and clinical factors among adult patients with diabetes in Poland. In order to demonstrate the assumed differentiation of the achieved study results depending on gender, the patients were divided into groups of women and men.

\section{MATERIALS AND METHOD}

Participants. The study was performed among 330 patients with T1DM and T2DM - 115 patients with T1DM aged $29.8 \pm 8.2$ (mean \pm SD) including 57 women and 58 men; 215 patients with T2DM aged $52.2 \pm 8.5-114$ women and 101 men. Considering the fact that $9 \%$ of the population in Poland suffer from diabetes [1] with the assumption that the maximum error is $3 \%$ and the confidence level is $90 \%$, the minimum sample size is estimated to be 245 persons. Thus the size of the investigated sample was sufficient for the analysis. All the participants were patients of the Diabetic Clinic of the Regional Hospital in Bielsko-Biala and the Diabetic Clinic of the Medi-Diab Non-Public Medical Center in Katowice. The research was carried out in the period from March 2016 - January 2017.

The screening examination comprised consecutive patients of the diabetes clinic who met the 18-60 age requirement. The patients with T1DM were selected out of 111 randomly chosen women and 115 men with T1DM, while the patients with T2DM were selected from 151 randomly chosen women and 145 men with T2DM. The reasons for reducing the number of patients qualified for further studies were a lack of consent (23 women and 25 men with T1DM, 19 women and 21 men with T2DM), incompletely filled surveys ( 25 women and 27 men with T1DM, 12 women and 16 men with T2DM). This reduction also resulted from taking into consideration the research inclusion and exclusion criteria: in T1DM in women - hyperthyroidism (1 person), taking sedative or psychotropic drugs (3) and glucocorticoids (2), in men - alcoholism (3 persons), neoplasm (1), glucocorticoids (1); in T2DM in women - hyperthyroidism (1 person), hypothyroidism (1), neoplasm (1), taking a sedative or psychotropic drugs (2) and alcoholism (1); in men - alcoholism (3 persons), neoplasm (2), and taking immunosuppressive drugs (2).

The inclusion criteria for the groups of studied patients were the occurrence of diabetes lasting for at least a year and the ability to complete a questionnaire written in Polish. Persons excluded from the study were patients with secondary diabetes, gestational diabetes, patients in whom acute inflammation requiring treatment had occurred during the last three months, patients taking immunosuppressive drugs, glucocorticoids, anti-inflammatory drugs, sedative and psychoactive drugs, as well as patients with diagnosed cancer, with function disorders of the thyroid and the adrenal glands, with alcoholism, and patients who did not provide consent for participating in the study. During the patient history taking (interview) and on the basis of the medical case record (medical history), chronic comorbidities, e.g. as coronary artery disease, heart failure, hypertension, renal failure and stroke, as well as late diabetes complications, such as retinopathy, nephropathy, polyneuropathy and diabetic foot were taken into account. Comorbidities and diabetes complications were diagnosed by specialist physicians, mainly internists, cardiologists, neurologists, nephrologists, diabetologists and ophthalmologists.

In patients with T1DM. the treatment of diabetes generally consisted in adhering to a diet and taking insulin, and in patients with T2DM it consisted in a diet and taking derivatives of sulfonylurea and biguanides, and in some cases insulin. All the patients attended the diabetes clinic more or less every three months. During the appointment at the clinic the patients had their glucose and HbAlc levels determined, their pharmacological treatment was established, and they underwent education activities aimed at adopting an appropriate diet, including the number of carbohydrate exchanges and food content considering carbohydrates, protein and fats. Aerobic physical training was also recommended to the patients.

The study was performed with the consent of the Bioethics Committee of the Beskidzka Regional Chamber 
of Physicians in Bielsko-Biala on 11 February 2016 (Consent No. 2016/02/11/1).

Method. The values of the glucose measures (fasting glycaemia and the concentration of glycated haemoglobin - HbAlc) were determined in all the studied persons. Systolic blood pressure and diastolic blood pressure were also measured.

Next, questionnaire studies were carried out using the following questionnaires: the patients' demographic and clinical data survey, Acceptance of Illness Scale (AIS), Beck Depression Inventory (BDI) and ADDQoL. The questionnaire also included brief information about personal data of each studied patient: age, gender, place of residence, education, marital status, professional activity, body mass, height, comorbidities, duration of diabetes, the occurrence of diabetes complications and medications taken.

The ADDQoL questionnaire (developed by Clare Bradley) is a tool specific for diabetes which is used for examining the QoL both in T1DM and T2DM patients [18]. It consists of two general questions referring to the QoL:1) determination of the measurement of the general, present level of QoL, which includes a 7-grade scale (excellent, very good, good, neither good nor bad, bad, very bad and extremely bad); 2) the specific influence of diabetes on QoL, which includes a 5 -grade scale (very much better, much better, a little better, the same and worse). The remaining components refer to the 19 domains of QoL without the disease and the influence of diabetes on the aspects of life. Each domain includes two components: Impact (from -3, maximum negative impact of diabetes, to +1 , positive impact of diabetes) and Importance (3 - very important, 0 - not at all important). The product of impact and importance ratings determines the value of the weighted impact (WI) score. This value may range from -9 to +3 for every examined domain of the ADDQoL. The lower the value of the weighted impact score, the worse the aspect of life within the scope of a given domain.

The average value of the weighted impact (AWI) score was also calculated for the whole scale. The AWI score is derived by dividing the sum of the weighted ratings by the number of applicable domains. The ADDQoL comprises the following domains: leisure activities, working life, journeys, holidays, physical health, family life, friendship and social life, personal relationship, sex life, physical appearance, self-confidence, motivation, people's reactions, feelings about future, financial situation, living conditions, dependence on others, freedom to eat and freedom to drink. The ADDQoL was applied in the studies with the consent and license received from the author, Clare Bradley (Health Psychology Research Unit, Royal Holloway, University of London via www.healthpsychologyresearch.com. The license for the Polish language version bore the number CB521). The studies applied the Polish language version of the ADDQoL, the psychometric properties of which, determined earlier, indicate that it is a reliable tool useful for the assessment of the level of QoL of adult patients in Poland with T1DM or T2DM [26].

The study applied the AIS scale created by Felton et al. and adapted to the Polish conditions by Juczynski [31]. It includes eight statements, for each of them the respondent assesses his or her current condition in a 5-point scale $(1-5)$. The total score of all the points is the general measure of the degree of acceptance of the illness; its scope ranges from $8-40$ points. A low result indicates lack of acceptance, adaptation to the illness, and a strong feeling of discomfort. A high result, in turn, indicates acceptance of the illness, which manifests itself with a lack of negative emotions related to the illness.

The BDI is a 21-point screening tool used for assessing the degree of severity of mood disorder symptoms (depression) [32]. The scores obtained in the BDI range from $0-63$, with higher score values indicating more severe symptoms of depression.

Before commencing the study, each patient was informed about its purpose by the authors (EB, DDM). The questionnaires were completed personally and anonymously by the patients during a visit by a physician. The time needed for filling in the survey was 20 - 30 minutes.

Statistical analysis. Statistical analysis was performed with Statistica v.10 StatSoft Polska software. The level of statistical significance assumed in all the calculations was $\alpha=0.05$. The mean value and the standard deviation were calculated for the quantitative data. The Mann-Whitney $\mathrm{U}$ test was applied in order to compare two independent groups characterized by distributions which were not normal. Normality of distributions was verified using the ShapiroWilk test. The Chi-square test or the Yates-corrected Chisquare test were used in order to verify the occurrence of correlations between the analyzed variables. Reliability of the scale was determined by calculating the alpha Cronbach coefficient. A logistic regression model was created in order to determine the risk factors for the occurrence of lower AWI values (greater negative impact of diabetes on the QoL). The significance of the model was verified using the $\chi^{2}$ likelihood ratio test, the $\mathrm{R}^{2}$ goodness of fit was determined, based on the Nagelkerke coefficient, and subsequently confirmed by the Hosmer-Lemeshow test.

\section{RESULTS}

The socio-demographic, clinical and biochemical characteristics, as well as the degree of acceptance of the illness and the occurrence of depression symptoms among the studied persons are shown in Table 1. In the group of patients with T1DM, men were characterized by a significantly higher $\mathrm{BMI}$ value and more frequent consumption of alcohol. The group of patients with T2DM demonstrated significant differentiation between men and women in terms of the place of residence (about $90 \%$ of the studied women and about $60 \%$ of the studied men inhabited rural areas), professional activity (nearly all of the studied women and nearly a half of the studied men were professionally active), alcohol consumption ( $25 \%$ of the studied women and nearly half of the studied men consumed alcohol), smoking cigarettes (there were more active and formed smokers among men than among whom research indicates that men), the concentration of HbAlc was higher in men, the frequency of occurrence of comorbidities (hypertension, heart failure, renal failure) was higher in men, whereas the values of the BDI scores were higher in women (Tab. 1).

'Good', 'very good' and 'excellent' levels of the present general QoL were declared by $72 \%$ of women and $69 \%$ of men with T1DM, and $65 \%$ of women and $52 \%$ of men with T2DM (Tab. 2). When the studied patients were asked how their QoL would change if they did not have diabetes, the majority answered that their QoL would improve: $81 \%$ of women and $83 \%$ of men with T1DM and $78 \%$ of women 
Table 1. Socio-demographic, clinical and biochemical characteristics, occurrence of depression, degree of acceptance of diabetes (mean \pm standard deviation

\begin{tabular}{|c|c|c|c|c|c|c|c|}
\hline \multirow[b]{2}{*}{ Parameter } & & \multicolumn{2}{|c|}{ Type 1 diabetes } & \multicolumn{4}{|c|}{ Type 2 diabetes } \\
\hline & & $\begin{array}{l}\text { Female } \\
(n=57)\end{array}$ & Male $(n=58)$ & $\mathrm{p}$ & $\begin{array}{l}\text { Female } \\
(n=114)\end{array}$ & $\begin{array}{c}\text { Male } \\
(n=101)\end{array}$ & $\mathrm{p}$ \\
\hline Age (years) & & $31.5 \pm 8.9$ & $28.2 \pm 7.1$ & 0.0629 & $51.1 \pm 9.7$ & $53.4 \pm 6.8$ & 0.1459 \\
\hline Body mass index $\left(\mathrm{kg} / \mathrm{m}^{2}\right)$ & & $23.7 \pm 3.8$ & $26.0 \pm 3.6$ & 0.0011 & $28.8 \pm 5.4$ & $30.2 \pm 5.6$ & 0.1116 \\
\hline Education & Vocational and Primary/Pre-university/Higher & $13 / 24 / 20$ & $17 / 18 / 23$ & 0.4513 & $70 / 34 / 10$ & $52 / 36 / 13$ & 0.3124 \\
\hline Marital status & Single/Married/Widower/Divorced & $14 / 39 / 0 / 4$ & $18 / 35 / 2 / 3$ & $\mathrm{nc}$ & $3 / 109 / 0 / 2$ & $11 / 83 / 2 / 5$ & nc \\
\hline Professional activity & Currently working/Not working & $43 / 14$ & $48 / 10$ & 0.3341 & $113 / 1$ & $48 / 53$ & $<0.0001^{*}$ \\
\hline Smoking & Never/Past/Present & $27 / 15 / 15$ & $15 / 19 / 24$ & 0.0506 & $72 / 21 / 21$ & $23 / 44 / 34$ & $<0.0001$ \\
\hline Alcohol & Drinking/Not drinking & $28 / 29$ & $39 / 19$ & 0.0488 & $29 / 85$ & $48 / 53$ & 0.0007 \\
\hline $\begin{array}{l}\text { Diabetes duration } \\
\text { (years, } x \pm S D \text { ) }\end{array}$ & & $10.0 \pm 7.4$ & $8.6 \pm 7.1$ & 0.2632 & $8.9 \pm 6.6$ & $9.9 \pm 7.6$ & 0.5480 \\
\hline \multirow{4}{*}{ Comorbidities } & Coronary artery disease & 1 & 0 & $\mathrm{nc}$ & 23 & 32 & 0.0536 \\
\hline & Hypertension & 9 & 4 & $0.2258^{*}$ & 62 & 74 & 0.0042 \\
\hline & Heart failure & 1 & 0 & $\mathrm{nc}$ & 11 & 22 & 0.0138 \\
\hline & Renal failure & 0 & 1 & $\mathrm{nc}$ & 7 & 19 & $0.0084^{*}$ \\
\hline Drugs & Oral antidiabetic/insulin/ antihiper-tensive/statins & $6 / 57 / 9 / 0$ & $4 / 58 / 4 / 0$ & $\mathrm{nc}$ & $\begin{array}{c}114 / 43 / \\
64 / 43\end{array}$ & $\begin{array}{c}101 / 57 / \\
80 / 54\end{array}$ & nc \\
\hline Complications of diabetes & Retinopathy/nephropathy/polyneuropathy/diabetic foot & $10 / 0 / 5 / 1$ & $10 / 0 / 2 / 0$ & $\mathrm{nc}$ & $29 / 8 / 17 / 4$ & $31 / 13 / 18 / 4$ & nc \\
\hline Glucose fasting (mg/dL) & & $121.4 \pm 23.1$ & $120.4 \pm 25.6$ & 0.2632 & $126.9 \pm 29.9$ & $132.5 \pm 31.1$ & 0.0932 \\
\hline $\mathrm{HbA} 1 \mathrm{c}(\%, x \pm \mathrm{SD})$ & & $6.11 \pm 0.98$ & $5.96 \pm 1.00$ & 0.2216 & $6.47 \pm 1.23$ & $6.88 \pm 1.32$ & 0.0116 \\
\hline BDI (scores) & & $8.2 \pm 8.1$ & $5.9 \pm 6.0$ & 0.133 & $12.9 \pm 8.3$ & $9.9 \pm 9.5$ & 0.0285 \\
\hline AIS (scores) & & $32.5 \pm 6.9$ & $33.8 \pm 5.9$ & 0.4723 & $27.7 \pm 8.3$ & $29.0 \pm 8.4$ & 0.2241 \\
\hline
\end{tabular}

$\mathrm{HbA1c}=$ glycated haemoglobin; BDI = Beck Depression Inventory; AIS = Acceptance of IIIness Scale; $p=$ statistical significance of differences; ${ }^{*}$ Yates-corrected Chi-square test, $\mathrm{nc}=$ not calculated

Table 2. General quality of life of men and women with diabetes

\begin{tabular}{|c|c|c|c|c|}
\hline & \multicolumn{2}{|c|}{ Type 1 Diabetic Patients } & \multicolumn{2}{|c|}{ Type 2 Diabetic Patients } \\
\hline & Female $(n=57)$ & Male $(\mathrm{n}=58)$ & Female $(n=114)$ & Male $(n=101)$ \\
\hline In general, my present quality of life is: & \multicolumn{4}{|c|}{$\mathrm{N}(\%)$} \\
\hline Excellent $(+3)$ & $1(1.8)$ & $2(3.5)$ & $1(0.9)$ & $0(0.0)$ \\
\hline Very good (+2) & $12(21.1)$ & $18(31.0)$ & 15(13.2) & $13(12.9)$ \\
\hline Good (+1) & $28(49.1)$ & 2034.5) & $58(50.9)$ & 40(39.6) \\
\hline Neither good nor bad (0) & 14(24.6) & $17(29.3)$ & $32(28.1)$ & $31(30.7)$ \\
\hline $\operatorname{Bad}(-1)$ & $2(3.5)$ & $1(1.7)$ & $7(6.1)$ & 15(14.9) \\
\hline Very bad $(-2)$ & $0(0.0)$ & $0(0.0)$ & $0(0.0)$ & $2(2.0)$ \\
\hline Extremely bad $(-3)$ & $0(0.0)$ & $0(0.0)$ & $1(0.9)$ & $0(0.0)$ \\
\hline mean \pm standard deviation & $0.93 \pm 0.82$ & $1.05 \pm 0.91$ & $0.71 \pm 0.87$ & $0.47 \pm 0.97^{*}$ \\
\hline statistical significance of differences $(p)$ & \multicolumn{2}{|c|}{0.5255} & \multicolumn{2}{|c|}{0.0747} \\
\hline If I did not have diabetes, my quality of life would be: & & \multicolumn{3}{|c|}{$n(\%)$} \\
\hline Very much better $(-3)$ & $6(10.5)$ & $6(10.3)$ & $11(9.7)$ & 12(11.9) \\
\hline Much better (-2) & $17(29.8)$ & $13(22.4)$ & $31(27.2)$ & 39(38.6) \\
\hline A little better $(-1)$ & $23(40.4)$ & $29(50.0)$ & $47(41.2)$ & 35(34.7) \\
\hline The same (0) & $11(19.3)$ & 10(17.2) & $25(21.9)$ & 14(13.9) \\
\hline Worse (1) & $0(0.0)$ & $0(0.0)$ & $0(0.0)$ & $1(1.0)$ \\
\hline mean \pm standard deviation & $-1.32 \pm 0.91$ & $-1.26 \pm 0.87$ & $-1.25 \pm 0.91$ & $-1.47 \pm 0.91$ \\
\hline statistical significance of differences $(p)$ & \multicolumn{2}{|c|}{0.7016} & \multicolumn{2}{|c|}{0.0684} \\
\hline
\end{tabular}

${ }^{*} \mathrm{p}<0.001$ compared to men with type 1 diabetes 
and $86 \%$ of men with T2DM, respectively. The values of the general- and diabetes-specific QoL proved to be comparable in men and women in both types of diabetes ( $\mathrm{p}>0.05$; Tab. 2 ).

Tables 3 and 4 present the components of ADDQoL, i.e. the impact and importance rating together with the weighted impact score for T1DM and T2DM. It was demonstrated that in both studied groups of patients with diabetes the values of the impact rating and WI score were negative for all the domains of the ADDQoL. "Not applicable" replies for the impact rating indicator were provided by the patients with T1DM most frequently in the following domains: "working life" (9.5\% of respondents), "holidays" (4.8\%) and "personal relationship" (4.8\%), whereas in case of T2DM in the following domains: "working life" (36.3\% of respondents), "sex life" (8.4\%), "holidays" (7.9\%), "personal relationship" (6.1\%) and "people's reactions" (6.1\%). In the case of T1DM, the negative values of the WI score in the scope of the analyzed domains in women ranged from -1.33 ("living conditions") to -3.23 ("feelings about the future"), and in men - from -1.16 ("living conditions") to - 4.05 ("freedom to eat"). In this type of diabetes, significant differences were observed between men and women in the following domains: "working life" and "freedom to eat" ( $p<0.05$; Tab. 3 - 4). In the case of T2DM, the negative values of the WI score in the scope of the analyzed domains: in women from -1.34 ("living conditions") to -3.82 ("freedom to eat"), and similarly in men - from -1.05 ("living conditions") to -4.64 ("freedom to eat"). In this type of diabetes significant differences were observed between men and women in the following domains: "leisure activities", "working life", "sex life", "self-confidence", "dependence on others" and "freedom to eat" $(\mathrm{p}<0.05-0.01$; Tab. 3 - 4)
In the case of T1DM, the AWI values were $-2.38 \pm 1.80$ for women and $-2.10 \pm 1.37$ for men, and were statistically comparable ( $p>0.05)$. In the case of T2DM, these values were significantly lower in men $(-2.60 \pm 1.66)$ than in women $(-2.07$ $\pm 1.57)(\mathrm{p}<0.05)$.

The overall reliability coefficients (Cronbach's alpha) of the ADDQoL were 0.92 in the group with T1DM and 0.93 in the group with T2DM, thus indicating good internal consistency.

In order to demonstrate potential associations between the level of QoL and some of the socio-demographic and clinical data, the studied patients were divided into those with a lower AWI score $(<3.0)$ and a higher AWI score $(\geq-$ 3.0). Except for the differentiated value of the AWI in men with T2D depending on the consumption of alcohol, the studied patients did not demonstrate any significant changes in terms of the influence of the level of education, place of residence, marital status, smoking cigarettes, occurrence of arterial hypertension, and taking antihypertensive drugs on the QoL was determined using the AWI score (Tab. 5 - 6).

The applied logistic regression model verified whether any of the analyzed factors - gender, age, BMI, concentration of glycated haemoglobin (HbAlc), duration of diabetes, its complications, BDI and AIS point scores and the mean arterial pressure - may lead to deterioration of the QoL determined by a lower AWI value. Significant deterioration of the QoL was observed in patients with T1DM with complications of this disease (odds ratio: 5.67, $\mathrm{p}=0.0067$ ) (Tab. 7). In this group, the model created was statistically significant and proved by the result of the likelihood ratio test $\left(\chi^{2}=17.00 ; p=\right.$ 0.0487 ). The model's goodness of fit $-\mathrm{R}^{2}=0.25$ (Nagelkerke); sufficient goodness of fit was confirmed by the result of the Hosmer-Lemeshow test $(p=0.3069)$. In the group of patients

Table 3. Distribution of ADDQoL responses by impact, importance rating and weighted impact score for type 1 diabetes

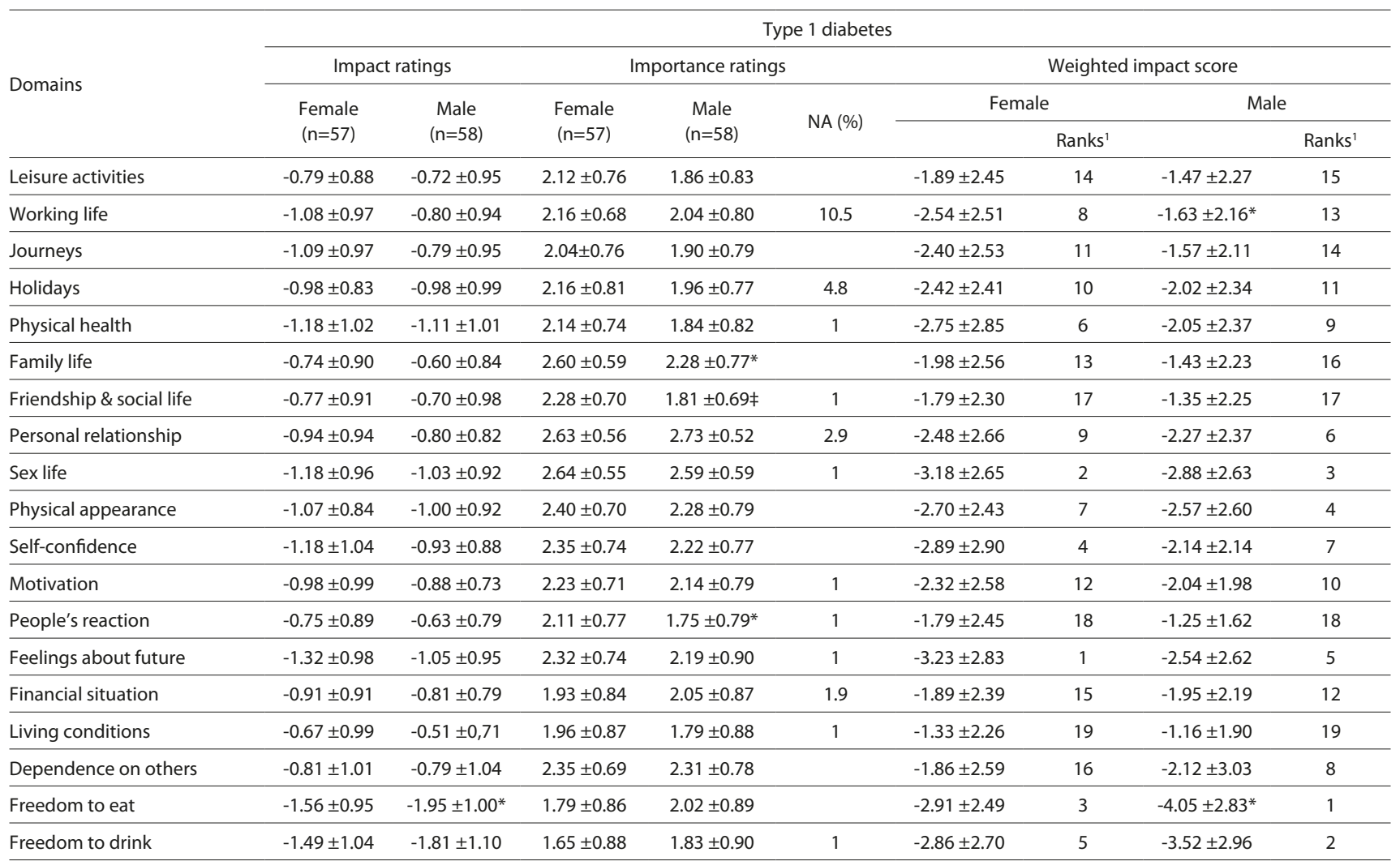


Table 4. Distribution of ADDQoL responses by impact, importance rating and weighted impact score for type 2 diabetes

\begin{tabular}{|c|c|c|c|c|c|c|c|c|c|}
\hline \multirow{4}{*}{ Domains } & \multicolumn{9}{|c|}{ Type 2 diabetes } \\
\hline & \multicolumn{2}{|c|}{ Impact ratings } & \multicolumn{3}{|c|}{ Importance ratings } & \multicolumn{4}{|c|}{ Weighted impact score } \\
\hline & \multirow{2}{*}{$\begin{array}{l}\text { Female } \\
(n=114)\end{array}$} & \multirow{2}{*}{$\begin{array}{c}\text { Male } \\
(n=101)\end{array}$} & \multirow{2}{*}{$\begin{array}{l}\text { Female } \\
(n=114)\end{array}$} & \multirow{2}{*}{$\begin{array}{c}\text { Male } \\
(n=101)\end{array}$} & \multirow{2}{*}{ NA (\%) } & \multicolumn{2}{|c|}{ Female } & \multicolumn{2}{|c|}{ Male } \\
\hline & & & & & & & Ranks' $^{1}$ & & Ranks' \\
\hline Leisure activities & $-0.95 \pm 0.99$ & $-1.30 \pm 1.12^{*}$ & $1.86 \pm 0.62$ & $1.76 \pm 0.76$ & 2,3 & $-1.82 \pm 2.22$ & 13 & $-2.50 \pm 2.74^{*}$ & 12 \\
\hline Working life & $-0.97 \pm 0.97$ & $-1.40 \pm 1.16$ & $2.12 \pm 0.78$ & $2.10 \pm 0.76$ & 36,3 & $-2.14 \pm 2.47$ & 8 & $-3.25 \pm 3.13^{*}$ & 3 \\
\hline Journeys & $-1.05 \pm 0.97$ & $-1.31 \pm 1.13$ & $1.64 \pm 0.73$ & $1.60 \pm 0.83$ & 0,5 & $-1.86 \pm 2.00$ & 10 & $-2.39 \pm 2.72$ & 14 \\
\hline Holidays & $-0.96 \pm 0.94$ & $-1.33 \pm 1.01^{*}$ & $1.92 \pm 0.74$ & $1.95 \pm 0.73$ & 8,8 & $-2.09 \pm 2.44$ & 9 & $-2.75 \pm 2.60$ & 6 \\
\hline Physical health & $-1.14 \pm 0.94$ & $-1.37 \pm 0.94$ & $1.93 \pm 0.71$ & $1.80 \pm 0.70$ & 0,9 & $-2.35 \pm 2.42$ & 4 & $-2.68 \pm 2.37$ & 10 \\
\hline Family life & $-0.72 \pm 0.91$ & $-0.90 \pm 0.98$ & $2.46 \pm 0.63$ & $2.28 \pm 0.69$ & & $-1.84 \pm 2.54$ & 11 & $-1.96 \pm 2.39$ & 17 \\
\hline Friendship \& social life & $-0.82 \pm 0.99$ & $-1.02 \pm 0.90$ & $2.11 \pm 0.64$ & $1.89 \pm 0.72$ & 0,9 & $-1.77 \pm 2.25$ & 16 & $-2.03 \pm 2.22$ & 16 \\
\hline Personal relationship & $-0.79 \pm 1.00$ & $-1.07 \pm 1.04^{*}$ & $2.45 \pm 0.71$ & $2.38 \pm 0.68$ & 6,5 & $-1.81 \pm 2.56$ & 14 & $-2.53 \pm 2.79$ & 11 \\
\hline Sex life & $-0.90 \pm 0.97$ & $-1.47 \pm 1.07 \ddagger$ & $1.88 \pm 0.86$ & $1.97 \pm 0.80$ & 8,8 & $-1.83 \pm 2.41$ & 12 & $-3.04 \pm 2.87 \dagger$ & 5 \\
\hline Physical appearance & $-1.01 \pm 1.03$ & $-1.08 \pm 1.04$ & $2.16 \pm 0.78$ & $1.80 \pm 0.75 \ddagger$ & 0,5 & $-2.29 \pm 2.77$ & 5 & $-2.37 \pm 2.85$ & 15 \\
\hline Self-confidence & $-0.89 \pm 0.94$ & $-1.25 \pm 1.03^{*}$ & $1.95 \pm 0.73$ & $1.94 \pm 0.65$ & 0,5 & $-1.81 \pm 2.33$ & 15 & $-2.71 \pm 2.75 \dagger$ & 8 \\
\hline Motivation & $-1.11 \pm 0.91$ & $-1.35 \pm 0.98$ & $1.96 \pm 0.65$ & $1.92 \pm 0.65$ & 1,4 & $-2.25 \pm 2.26$ & 6 & $-2.71 \pm 2.51$ & 9 \\
\hline People's reaction & $-0.71 \pm 0.93$ & $-0.83 \pm 0.88$ & $1.86 \pm 0.80$ & $1.55 \pm 0.70 \dagger$ & 0,9 & $-1.46 \pm 2.25$ & 17 & $-1.49 \pm 1.96$ & 18 \\
\hline Feelings about future & $-1.18 \pm 0.88$ & $-1.40 \pm 1.02$ & $2.09 \pm 0.80$ & $1.95 \pm 0.78$ & 0,9 & $-2.63 \pm 2.29$ & 3 & $-3.10 \pm 2.95$ & 4 \\
\hline Financial situation & $-0.96 \pm 0.92$ & $-1.22 \pm 0.95^{*}$ & $2.17 \pm 0.65$ & $2.16 \pm 0.65$ & 0,5 & $-2.20 \pm 2.38$ & 7 & $-2.73 \pm 2.38$ & 7 \\
\hline$\underline{\text { Living conditions }}$ & $-0.63 \pm 0.89$ & $-0.58 \pm 0.82$ & $2.14 \pm 0.74$ & $1.98 \pm 0.75$ & 0,5 & $-1.34 \pm 2.15$ & 19 & $-1.05 \pm 1.77$ & 19 \\
\hline Dependence on others & $-0.72 \pm 0.88$ & $-1.11 \pm 1.09^{*}$ & $2.21 \pm 0.75$ & $2.06 \pm 0.77$ & 1,4 & $-1.46 \pm 2.01$ & 18 & $-2.49 \pm 2.95 \dagger$ & 13 \\
\hline$\underline{\text { Freedom to eat }}$ & $-1.77 \pm 0.92$ & $-2.03 \pm 0.87^{*}$ & $1.98 \pm 0.75$ & $2.16 \pm 0.66$ & 0,9 & $-3.82 \pm 2.63$ & 1 & $-4.64 \pm 2.72^{*}$ & 1 \\
\hline Freedom to drink & $-1.40 \pm 1.04$ & $-1.60 \pm 1.38$ & $1.67 \pm 0.71$ & $1.80 \pm 0.68$ & 0,9 & $-2.67 \pm 2.42$ & 2 & $-3.26 \pm 2.88$ & 2 \\
\hline
\end{tabular}

$\mathrm{NA}=$ not applicable response; ${ }^{1}=$ values of Ranks range from 1-19; Mann-Whitney U test, compared to studied women $*=\mathrm{p}<0.05 ; \dagger=\mathrm{p}<0.01 ; \ddagger=\mathrm{p}<0.001$

Table 5. Socio-demographic and clinical data of patients with T1DM with values of AWI score of ADDQoL scale

\begin{tabular}{|c|c|c|c|c|c|c|c|}
\hline \multirow{4}{*}{ Parametr } & & \multicolumn{6}{|c|}{ Type 1 diabetes } \\
\hline & & \multicolumn{3}{|c|}{ Female $(n=57)$} & \multicolumn{3}{|c|}{ Male $(n=58)$} \\
\hline & & \multicolumn{3}{|c|}{ AWI } & \multicolumn{3}{|c|}{ AWI } \\
\hline & & $\begin{array}{l}<-3.0 \\
(n=14)\end{array}$ & $\begin{array}{c}\geq-3.0 \\
(n=43)\end{array}$ & $\mathrm{p}$ & $\begin{array}{l}<-3.0 \\
(n=12)\end{array}$ & $\begin{array}{c}\geq-3.0 \\
(\mathrm{n}=46)\end{array}$ & $\mathrm{p}$ \\
\hline Education & Primary/Preuniversity/Higher & $2 / 8 / 4$ & $11 / 16 / 16$ & $0.495^{2}$ & $5 / 2 / 5$ & $12 / 16 / 18$ & $0.395^{2}$ \\
\hline Marital status & Separated, divorced, widower/Married, in a relationship & $4 / 10$ & $14 / 29$ & $0.999^{2}$ & $6 / 6$ & $17 / 29$ & $0.513^{2}$ \\
\hline Smoking & Yes/No & $2 / 12$ & $13 / 30$ & $0.312^{2}$ & $6 / 6$ & $18 / 28$ & $0.527^{2}$ \\
\hline Drinking of alcohol & Yes/No & $5 / 9$ & $23 / 20$ & $0.397^{1}$ & $6 / 6$ & $33 / 13$ & $0.180^{2}$ \\
\hline Hypertension & Yes/No & $3 / 11$ & $6 / 37$ & $0.674^{2}$ & $2 / 10$ & $2 / 44$ & $0.186^{2}$ \\
\hline Antihypertensive drugs & Yes/No & $3 / 11$ & $6 / 37$ & $0.674^{2}$ & $2 / 10$ & $2 / 44$ & $0.186^{2}$ \\
\hline
\end{tabular}

$\mathrm{AWI}=$ values of the average weighted impact; $\mathrm{p}=$ statistical significance of differences; ${ }^{1}=$ Yate's-corrected Chi-square test; ${ }^{2}=$ Fischer's exact test

Table 6. Socio-demographic and clinical data of patients with T2DM with values of AWI score of ADDQoL scale

\begin{tabular}{|c|c|c|c|c|c|c|c|}
\hline \multirow{4}{*}{ Parameter } & & \multicolumn{6}{|c|}{ Type 2 diabetes } \\
\hline & & \multicolumn{3}{|c|}{ Female $(n=114)$} & \multicolumn{3}{|c|}{ Male $(n=101)$} \\
\hline & & \multicolumn{3}{|c|}{ AWI } & \multicolumn{3}{|c|}{ AWI } \\
\hline & & $\begin{array}{l}<-3.0 \\
(n=25)\end{array}$ & $\begin{array}{c}\geq-3.0 \\
(n=89)\end{array}$ & $\mathrm{p}$ & $\begin{array}{l}<-3.0 \\
(n=34)\end{array}$ & $\begin{array}{l}\geq-3.0 \\
(n=67)\end{array}$ & $\mathrm{p}$ \\
\hline Education & Primary/Preuniversity/Higher & $18 / 5 / 2$ & $52 / 29 / 8$ & $0.578^{2}$ & $16 / 11 / 7$ & $36 / 25 / 6$ & $0.423^{2}$ \\
\hline Place of residence & Rural/ Urban & $22 / 3$ & $82 / 7$ & $0.455^{3}$ & $18 / 16$ & $42 / 25$ & $0.346^{1}$ \\
\hline Marital status & Separated, divorced, widower/Married, in a relationship & $1 / 24$ & $4 / 85$ & $0.999^{3}$ & $8 / 26$ & $10 / 57$ & $0.428^{2}$ \\
\hline Smoking & Yes/No & $6 / 19$ & $15 / 74$ & $0.601^{2}$ & $10 / 24$ & $24 / 43$ & $0.519^{1}$ \\
\hline Drinking of alcohol & Yes/No & $9 / 16$ & $20 / 69$ & $0.266^{2}$ & $11 / 23$ & $37 / 30$ & $0.030^{1}$ \\
\hline Hypertension & Yes/No & $16 / 9$ & $46 / 43$ & $0.387^{2}$ & $27 / 7$ & $47 / 20$ & $0.450^{2}$ \\
\hline Antihypertensive drugs & Yes/No & $18 / 7$ & $46 / 43$ & $0.114^{2}$ & $29 / 5$ & $51 / 16$ & $0.416^{2}$ \\
\hline
\end{tabular}

$\mathrm{AWI}=$ values of the average weighted impact, $\mathrm{p}=$ statistical significance of differences; ${ }^{1}=$ Chi-square test, $^{2}=$ Yate' $\mathrm{s}$-corrected Chi-square test; ${ }^{3}$ Fischer's exact test 
Table 7. Logistic regression analysis: predictors of lower QoL according to ADDQoL score for type 1 and type 2 diabetes

\begin{tabular}{|c|c|c|c|c|c|c|}
\hline \multirow[b]{2}{*}{ Variable } & \multicolumn{6}{|c|}{ ADDQoL } \\
\hline & \multicolumn{3}{|c|}{$\begin{array}{l}\text { Type } 1 \text { diabetes }(n=115) \text { AWI } \\
(\geq-3.0, n=89 ;<-3.0, n=26)\end{array}$} & \multicolumn{3}{|c|}{$\begin{array}{l}\text { Type } 2 \text { diabetes }(n=215) \text { AWI } \\
(\geq-3.0, n=156 ;<-3.0, n=59)\end{array}$} \\
\hline Gender & 0.11 & $\begin{array}{c}1.21 \\
(0.39-3.80)\end{array}$ & 0.7382 & 4.39 & $\begin{array}{c}2.10 \\
(1.04-4.22)\end{array}$ & 0.0362 \\
\hline Age & 0.01 & $\begin{array}{c}1.00 \\
(0.91-1.09)\end{array}$ & 0.9418 & 0.58 & $\begin{array}{c}0.98 \\
(0.94-1.03)\end{array}$ & 0.4480 \\
\hline Body mass index & 0.69 & $\begin{array}{c}0.94 \\
(0.82-1.09)\end{array}$ & 0.4058 & 0.21 & $\begin{array}{c}1.01 \\
(0.95-1.08)\end{array}$ & 0.6460 \\
\hline $\mathrm{HbA} 1 \mathrm{c}$ & 0.77 & $\begin{array}{c}1.30 \\
(0.72-2.37)\end{array}$ & 0.3804 & 2.94 & $\begin{array}{c}1.29 \\
(0.96-1.72)\end{array}$ & 0.0864 \\
\hline Duration of diabetes & 1.58 & $\begin{array}{c}0.94 \\
(0.84-1.04)\end{array}$ & 0.2092 & 0.01 & $\begin{array}{c}1.00 \\
(0.95-1.05)\end{array}$ & 0.9198 \\
\hline Complications of diabetes & 7.36 & $\begin{array}{c}5.67 \\
(1.59-20.14)\end{array}$ & 0.0067 & 2.26 & $\begin{array}{c}1.69 \\
(0.85-3.37)\end{array}$ & 0.1327 \\
\hline Beck Depression Inventory & 0.10 & $\begin{array}{c}1.01 \\
(0.93-1.10)\end{array}$ & 0.7465 & 4.82 & $\begin{array}{c}2.05 \\
(2.01-2.09)\end{array}$ & 0.0281 \\
\hline $\begin{array}{l}\text { Acceptance } \\
\text { Illness Scale }\end{array}$ & 2.43 & $\begin{array}{c}0.92 \\
(0.83-1.02)\end{array}$ & 0.1190 & 1.22 & $\begin{array}{c}0.97 \\
0.93-1.02)\end{array}$ & 0.2689 \\
\hline Mean arterial pressure & 3.15 & $\begin{array}{c}1.05 \\
(0.99-1.11)\end{array}$ & 0.0760 & 0.08 & $\begin{array}{c}1.00 \\
(0.97-1.03)\end{array}$ & 0.7778 \\
\hline Nagelkerke $\mathrm{R}^{2}$ & & 0.25 & & & 0.20 & \\
\hline Chi' ${ }^{2}$ likelihood ratio test & & $17.00 ; p=0.0$ & & & $32.21 ; p=0.0$ & \\
\hline
\end{tabular}

$\mathrm{AWI}=$ average weighted impact, $\mathrm{OR}(95 \% \mathrm{Cl})=$ odds ratio $(95 \%$ confidence intervals $) ; \mathrm{p}=$ statistical significance of differences; HbA1c = glycated haemoglobin

with T2DM, deterioration of the QoL was significantly more intensified in men (odds ratio: $2.10, \mathrm{p}=0.0362$ ) and in patients with higher BDI values (odds ratio: $2.05 ; \mathrm{p}=0.0281$ ) (Tab. 7 ). In this group, the created model was statistically significant which was proved by the result of the likelihood ratio test $\left(\chi^{2}\right.$ $=32.21 ; \mathrm{p}=0.0002)$. The model's goodness of fit $-\mathrm{R}^{2}=0.20$ (Nagelkerke); sufficient goodness of fit was confirmed by the result of the Hosmer-Lemeshow test $(\mathrm{p}=0.5601)$.

\section{DISCUSSION}

The Polish language version of the ADDQoL applied in the presented study, with good internal consistency prove by the authors, constitutes a reliable tool for investigating the QoL of patients with T1DM and T2DM. In adult patients with diabetes, inhabitants of southern Poland, the study demonstrated a negative impact of both types of diabetes on all 19 items (domains) of ADDQoL, despite the fact that about $70 \%$ of the studied patients with T1DM and nearly $60 \%$ with T2DM declared at least a good level of their present general QoL. However, it has to be noted that over $80 \%$ of the studied patients stated that their QoL would be improved if they did not have diabetes. This may mean that $4 / 5$ of the studied patients with T1DM and T2DM has the feeling of an insufficient QoL as a result of the disease.

The effect of T1DM on the weighted impact of the ADDQoL proved to be differentiated in the scope of particular domains. The most unfavourable weighted impact score was observed in aspects of life such as "feelings about future", "sex life", "freedom to eat" and "self-confidence" in women, and "freedom to eat", "freedom to drink", "sex life" and "physical appearance" in men. The smallest influence of T1DM on the weighted impact score was found in patients of both genders in the scope of the following domains: "living conditions", "people's reactions" and "friendship and social life". In patients with T2DM of both genders, the most negative weighted impact scores were found in the following domains: "freedom to eat" and "freedom to drink", as well as in the scope of "feelings about the future" in women, and "working life" in men.

It should also be noted that the value of "freedom to eat" was significantly lower in men than in women in both types of diabetes. This may mean that nutrition limitations (dietary restrictions) were more difficult for men with diabetes to cope with, than for women. In the majority of other studies which included studying the QoL using the ADDQoL in patients in various countries, similar results were also obtained in terms of the biggest negative impact of diabetes on the "freedom to eat" domain. The lowest or low mean weighted impact scores for this domain were calculated in patients with T2DM in Slovenia [6, 22], Greece [7], Malaysia [13], Turkey [14], Korea [11], Taiwan [16], Argentina [9], China [21], and in patients in multicentre studies in Turkey and in eight countries of western Europe [4], and in total for patients with both types of diabetes in Australia [12], Portugal [19] and Ireland [23].

The above results prove that the negative impact of diabetes on the QoL in the populations of many countries and in the current study - irrespective of gender and of the type of diabetes - proved to be common in the scope of the "freedom to eat" domain. The current study has also demonstrated that another domain which is strongly negatively affected by diabetes was "freedom to drink". Therefore in the declared domains of QoL, the patients with diabetes mostly indicated the limitations in food and liquid intake in terms of quantity and quality, as well as in terms of the time of a day. In relation 
to those results, it may be expected that the introduction of appropriate education and support directed at good nutrition adjusted to the individual preferences of patients with diabetes will lead to the improvement of their QoL, and even to an improvement in their glycaemic control.

With regard to the domains of the QoL in this study, which were affected by a highly negative influence of diabetes, it is necessary to mention "feelings about the future", "sex life" and "self confidence" in women, and "sex life", "physical appearance" and "feelings about the future" in men with T1DM, and in case of T2DM: "feelings about future", "physical health" and "physical appearance" in women, and "working life", "feelings about the future" and "sex life" in men. It should be noted that among patients with T2DM, men more strongly than women mentioned the aspects of life which relate to professional activity and sexuality, which is convergent with providing "not applicable" answers for the importance rating of ADDQoL equal $36.3 \%$ of respondents in the "working life" domain and $8.8 \%$ in the "sex life" domain in this group of patients. Similar percentage values of the "not applicable" option in T2DM were observed by Wang et al. [16] in the "working life" and "sex life" domains, in 27.3\% and 10.9\% of respondents, respectively, and an even higher percentage of these values was demonstrated by Bradley et al. [4] - 68\% for "working life" and 38\% for "sex life". Perhaps this was associated with the age of the studied patients because the respondents in the studies performed by Bradley et al. [4] were, on average, 14 years older than the patients in the current study. It may be supposed that the difference in the intensity degree of the influence of diabetes on particular domains of the QoL in the current study was related, among others, to the age of the studied patients (age difference between the patients with T1DM and T2DM, on average, was about 22 years). A highly negative impact of T1DM on the value of the "sex life" domain, both in women and in men, is convergent with the results obtained by the authors of the current study which demonstrated that among patients with T1DM, sexual disorders occurred in $35 \%$ of the studied women and erection disorders occurred in $50 \%$ of the studied men [33].

Own research indicates that patients of both genders with T1DM and T2DM diabetes had the least negative influence on the aspects of life related to "living conditions" and "people's reactions", as well as to "friendship and social life", which suggests that patients with diabetes in Poland defined their social problems as least negatively impacted by diabetes. Similar results in the scope of some of these domains in patients with diabetes have also been described by other authors $[6,12,13,17,22]$.

This study has demonstrated that the socio-demographic parameters investigated (education, place of residence, marital status, smoking) and clinical parameters (hypertension, antihypertensive drugs) were not associated with lower $(<-$ $3.0)$ or higher $(\geq-3.0)$ values of the AWI determining the level of QoL. In the case of T2DM, Ozder et al. [14] also did not demonstrate a significant connection between the socio-demographic parameters (e.g. gender, age, marital status, income) and the AWI scores of the ADDQoL. The results of studies conducted by Collins et al. [23] indicate that socio-demographic factors (gender, education, marital status, employment) did not modify the negative influence of diabetes on QoL.

The results of the logistic regression analysis in the presented study indicate an association between the lower values of the AWI scores $(<-3.0)$ of the ADDQoL with the occurrence of complications (complications of diabetes were the consequence of microvascular changes, and the mentioned visual disturbances were associated with diabetes by the ophthalmologists performing examinations) of T1DM and with male gender and the presence of depression symptoms in patients with T2DM. In patients with T2DM who demonstrated higher values in the BDI scores - which indicated the occurrence of depression symptoms - worse QoL was observed which was expressed by lower AWI values. The associations between the lowering of the level of QoL determined using the ADDQoL, and the occurrence of depression in patients with T2DM, have also been demonstrated by other authors $[8,10,15]$. This suggests the influence of the lowered mood on the reduction of QoL related to diabetes. In studies conducted by Wang et al. [16], patients with T2DM with complications showed a larger negative impact of diabetes on AWI scores, although the difference did not reach significance for the AWI scores; these results were convergent with those obtained in the current study. A lack of a significant correlation between the AWI scores and the occurrence of diabetic complications was also demonstrated by Kong et al. [17]. Also, Da Costa et al. [9] did not observe significant differences in the values of all the domains of the ADDQoL in patients with diabetes $(27 \%$ of persons had T1DM, 73\% of persons - T2DM) without and with complications. Similar to the current study, Papazafiropoulou et al. [7] - with the use of the logistic regression analysis - demonstrated a lack of significant associations between QoL and the duration of diabetes, BMI, HbAlc, smoking habits, education level and diabetic complications in patients with T2DM.

No statistical associations were found in this study between the AWI scores and the degree of acceptance of the illness. This may mean that the QoL of patients with T1DM or T2DM is independent from the declared degree of illness acceptance.

The obtained results indicate that in the group of persons with diabetes in Poland there are areas which require individual actions, and actions comprising society in general. Health education, as well as support directed at proper nutrition and physical and professional activity, may lead to quality improvement in many aspects in the life and health of patients with diabetes. The research indicates that in some of the domains (especially "freedom to eat") of the ADDQoL, men with diabetes demonstrated worse results than the studied women, which was perhaps associated with insufficient respect for recommendations by the men.

The presented study has several limitations. Firstly, it did not apply education in accordance with the Dose Adjustment For Normal Eating (DAFNE) promoting dietary freedom, improved QoL and glycaemic control in patients with T1DM [34], because this education model is not widespread in Poland. The patients in Poland undergo an individualized training adjusted to nutrition behaviours and to the caloric demand, taking into consideration appropriate proportions in the content of carbohydrates, protein and fats. However, due to difficulties in determining precise data related to individualized nutrition, this topic has not been considered in the presented study. It was also not possible to precisely determine the energy expenditure related to the physical training. Moreover, the oral anti-diabetic medications taken and insulin have not been taken into consideration in the logistic regression model, due to the lack of precise 
data, because during the observation of the progress of the disease in some patients the medication dosage was changed appropriate to the glycaemia and to the HbAlc concentration. It should be mentioned that the population of patients with T1DM and T2DM examined in the current study was representative for the patients with diabetes in Poland, especially in terms of the method of treatment and lifestyle. Another limitation is the selection of patients coming from specialist diabetologic units who were under constant medical supervision - due to this fact these patients were not representative of the whole population which includes also patients who do not use specialist care. Thirdly, it was not possible to compare the study results between the groups with T1DM and T2DM because these groups differed in terms of, e.g. age, BMI, mode of treatment, and the occurrence of complications and the symptoms of depression.

An assessment of the QoL was conducted among 50 patients with T2DM using the SF-36 questionnaire in the Polish study by Głowacka et al. [28]. The analysis showed that the questionnaire was able to identify the areas of health that require specific actions that concern the psychological domain. Similar results were obtained in own studies indicating depression as a risk factor that negatively affects the QoL in patients with T2DM. A different study result was presented by Kocka et al. [29] in a group of 103 patients with T2DM, which proved that the overall QoL of respondents was assessed higher in the psychological domain, while the lower scores were assigned to the domain of physical functioning.

\section{CONCLUSIONS}

Diabetes negatively affects the QoL of patients with T2DM in Poland. This negative impact is most significant in the following domains: freedom to eat, freedom to drink and sex life in both genders in T1DM, and freedom to eat, freedom to drink and feelings about the future in both genders, as well as working life and sex life in men with T2DM. The risk factors for worse quality of life are the occurrence of diabetes complications in patients with T1DM, as well as male gender and depression in patients with T2DM.

\section{Ethics approval}

The study was performed with the consent of the Bioethics Committee of the Beskidzka Regional Chamber of Physicians in Bielsko-Biala on 11 February 2016 (Consent No. 2016/02/11/1). The study does not report on or involve the use of any animals.

\section{Conflicts of Interest}

The authors declare no conflict of interest, neither financial nor non-financial, and received no funds from sponsors. The study was entirely self-financed. The design of the study, the collection, analyses, interpretation of data, writing of the manuscript, and the decision to publish the results were performed only by the authors. The study does not contain data from any individual person and data obtained from the questionnaires is freely available upon request.

\section{REFERENCES}

1. Statistical Report: Diabetes statistics in Poland and in the world. [in Polish] http://cukrzycapolska.pl/cukrzyca/statystyki. Accessed on 03 November 2018.

2. Ashwell S, Bradley C, Stephens JW, Witthaus E, Home PD. Treatment satisfaction and quality of life with insulin glargine plus insulin lispro compared with NPH insulin plus unmodified human insulin in individuals with type 1 diabetes. Diabetes Care. 2008; 31(6): 1112-1117.

3. Cooke D, O'Hara MC, Beinart N, Heller S, La Marca R, Byrne M, et al. Linguistic and psychometric validation of the Diabetes-Specific Quality-of-life Scale in U.K. English for adults with type 1 diabetes. Diabetes Care. 2013; 36(5): 1117-1125.

4. Bradley C, Eschwège E, de Pablos-Velasco P, Parhofer KG, Simon $\mathrm{D}$, Vandenberghe $\mathrm{H}$, et al. Predictors of Quality of Life and Other Patient-Reported Outcomes in the PANORAMA Multinational Study of People with Type 2 Diabetes. Diabetes Care. 2018; 41(2): 267-276. doi: $10.2337 /$ dc16-2655.

5. Wang HF, Yeh MC. The quality of life of adults with type 2 diabetes in a hospital care clinic in Taiwan. Qual Life Res. 2013; 22(3): 577-584.

6. Turk E, Prevolnik Rupel V, Tapajner A, Leyshon S, Isola A. An Audit of Diabetes Dependent Quality of Life (ADDQOL) in older patients with diabetes mellitus type 2 in Slovenia. Value Health Reg Issues. 2013; 2: 248-253.

7. Papazafiropoulou AK, Bakomitrou F, Trikallinou A, Ganotopoulou A, Verras C, Christofilidis G, et al. Diabetes-dependent quality of life (ADDQOL) and affecting factors in patients with diabetes mellitus type 2 in Greece. BMC Res Notes. 2015; 8: 786, doi: 10.1186/s13104-015-1782-8.

8. Timar R, Velea I, Timar B, Lungeanu D, Oancea C, Roman D, et al. Factors influencing the quality of life perception in patients with type 2 diabetes mellitus. Patient Prefer Adherence. 2016; 10: 2471-2477.

9. Pichon-Riviere A, Irazola V, Beratarrecheal A, Alcaraz A, Carrara C. Quality of life in type 2 diabetes mellitus patients requiring insulin treatment in Buenos Aires, Argentina: a cross-sectional study. Int J Health Policy Manage. 2015; 4(7): 475-480.

10. Lemon SC, Rosal MC, Welch G. Measuring quality of life in low-income, Spanish speaking Puerto Ricans with type 2 diabetes residing in the mainland U.S. Qual Life Res. 2011; 20: 1507-1511.

11. Chung JO, Cho DH, Chung DJ, Chung MY. An assessment of the impact of type 2 diabetes on the quality of life based on age at diabetes diagnosis. Acta Diabetol. 2014; 51(6): 1065-1072.

12. Donald M, Dower J, Coll JR, Baker P, Mukandi B, Doi SAR. Mental health issues decrease diabetes-specific quality of life independent of glycaemic control and complications: findings from Australia's living with diabetes cohort study. Health Qual Life Out. 2013; 11: 170

13. Daher AM, AlMashoor SHA, Winn T. Performance of the Malay Audit of Diabetes Dependent Quality of Life-18 and associates of quality of life among patients with type 2 diabetes mellitus from Major Ethnic Groups of Malaysia. PLoS One. 2016, doi:10.1371/journal.pone.0163701.

14. Ozder A, Sekeroglu M, Eker HH. Quality of life and satisfaction with treatment in subjects with type 2 diabetes: results from primary health care in Turkey. Int J Clin Exp Med. 2014; 7(12): 5715-5722.

15. Chung JO, Cho DH, Chung DJ, Chung MY. Assessment of factors associated with the quality of life in Korean type 2 diabetic patients. Intern Med. 2013; 52: 179-185.

16. Wang HF, Bradley C, Chang TJ, Chuang LM, Yeh, MC. Assessing the impact of diabetes on quality of life: validation of the Chinese version of the 19-item Audit of Diabetes-Dependent Quality of Life for Taiwan. Int J Qual Health Care. 2017; 29(3): 335-342.

17. Kong D, Ding Y, Zuo X, Su W, Xiu L, Lin M, et al. Adaptation of the Audit of Diabetes Dependent Quality of Life questionnaire to people with diabetes in China. Diabetes Res Clin Pract. 2011; 94: 45-52.

18. Bradley C, Todd C, Gordon T, Symonds E, Martin A, Plowright R. The development of an individualized questionnaire measure of perceived impact of diabetes on quality of life; the ADDQOL. Qual Life Res. 1999; 8: 79-91.

19. daCosta FA, Guerreiro JP, Duggan C. An Audit of Diabetes Dependent Quality of Life (ADDQoL) for Portugal: exploring validity and reliability. Pharm Pract. 2006; 4(3): 123-128.

20. Johari N, Manaf ZA, Ibrahim N, Shahar S, Mustafa N. Predictors of quality of life among hospitalized geriatric patients with diabetes mellitus upon discharge. Clin Intervent Aging. 2016; 11: 1455-1461.

21. Soon SS, Goh SY, Bee YM, Poon JL, Li SC, Thumboo J, Wee HL. Audit of Diabetes-Dependent Quality of Life (ADDQoL) [Chinese Version for Singapore] questionnaire: reliability and validity among Singaporeans with type 2 diabetes mellitus. Appl Health Econ Health Policy. 2010; 8(4): 239-249. 
22. Turk E, Prevolnik-Rupel V, Tapajner A, Isola A. Reliability and validity of the Audit on Diabetes-Dependent Quality of Life (ADDQoL) and EQ-5D in elderly Slovenian diabetes mellitus type 2 patients. Health. 2014; 6: 699-711.

23. Collins MM, O'Sullivan T, Harkins V, Perry IJ. Quality of life and quality of care in patients with diabetes experiencing different models of care. Diabetes Care. 2009; 32(4): 603-605.

24. Iversen MM, Espehaug B, Rokne B, Haugstvedt A, Graue M. Psychometric properties of the Norwegian version of the Audit of Diabetes-Dependent Quality of Life. Qual Life Res. 2013; 22: 2809-2812.

25. Ostini R, Dower J, Donald M. The audit of diabetes-dependent quality of life 19 (ADDQoL): feasibility, reliability and validity in a populationbased sample of Australian adults. Qual Life Res. 2012; 21: 1471-7.

26. Bąk E, Marcisz C, Nowak-Kapusta Z, Dobrzyn-Matusiak D, Marcisz E., Krzeminska S. Psychometric properties of the Audit of DiabetesDependent Quality of Life (ADDQoL) in a population-based sample of Polish adults with type 1 and 2 diabetes. Health Qual Life Out. 2018; 16(1): 53. doi: 10.1186/s12955-018-0878-y.

27. Chudiak A, Lomper K, Jankowska-Polanska B, Uchmanowicz I. The impact of diabetes education on the assessment of the quality of life of patients type 2 diabetes. Problemy Pielęgniarstwa 2015; (1): 1-6. [Polish]
28. Głowacka M, Roszak A, Kornatowski T, et al. Elderly patients’ quality of life as show on the example of HF and diabetes patients. Geriatria 2017; 11: 171-176. [Polish].

29. Kocka K, Bartoszek A, Ślusarska B et al. [The treatment, duration and complications of diabetes type 2 and the quality of life of the patients]. Med Rodz. 2017; 20(1): 9-16. [Polish]

30. Fal AM, Jankowska B, Uchmanowicz I, Sen M, Panaszek B, Polanski J. Type 2 diabetes quality of life patients treated with insulin and oral hypoglycemic medication. Act. Diab. 2011; 48(3): 237-42. doi: 10.1007/ s00592-010-0244-y.

31. Juczyński Z. Measurement tools in the promotion health; $1^{\text {st }}$ ed. Warszawa: The Psychological Tests Lab of the Polish Psychological Association; 2001. p. 171-174.

32. Beck AT, Steer RA, Brown GK. Manual for the Beck Depression Inventory-II. Psychological Corporation San Antonio, TX, USA; 1996.

33. Bąk E, Marcisz C, Krzeminska S, Dobrzyn-Matusiak D, Foltyn A, Drosdzol-Cop A. Does type 1 diabetes modify sexuality and mood of women and men? Int J Environ Res Public Health. 2018; 15: 598. doi: 10.3390/ijerph15050958.

34. DAFNE Study Group. Training in flexible, intensive insulin management to enable dietary freedom in people with type 1 diabetes: dose adjustment for normal eating (DAFNE) randomised controlled trial. BMJ. 2002; 5: 325(7367), 746. 